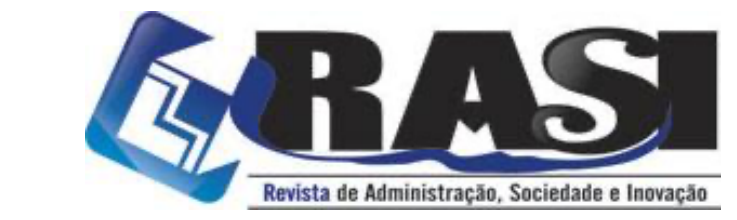

http://www.rasi.vr.uff.br

RASI, Volta Redonda/RJ, v. 8, n. 1, pp. 82-98, Jan./Abr. 2022

\title{
Análise das práticas de sustentabilidade e de racionalização do uso de materiais e serviços nos campi do IFMT a partir dos Planos de Logística Sustentável
}

\author{
Gleika Debacker (IFMT) - gleika.debacker@jna.ifmt.edu.br \\ Márcio Moutinho Abdalla (UFF) - marcioabdalla@id.uff.br \\ Caroline Gonçalves (UFMS) - goncalves.caroline@ufms.br
}

\begin{abstract}
Resumo:
Na elaboração do Plano de Logística Sustentável (PLS), dentre outras regras estabelecidas pela Instrução Normativa $\mathrm{N}^{\mathrm{o}} 10 / 2012$, deve-se observar os temas mínimos a serem abrangidos, para que estes possam direcionar as práticas de sustentabilidade e racionalização do uso de materiais e serviços. Nesse sentido, o objetivo deste trabalho é identificar e mapear as ações de sucesso e as dificuldades relacionadas às práticas de sustentabilidade e de racionalização do uso de materiais e serviços nos campi do Instituto Federal de Mato Grosso (IFMT), a partir do art. $8^{\circ}$ da IN N ${ }^{o} 10 / 2012$. A pesquisa classifica-se como qualitativa. Quanto aos objetivos, a pesquisa é exploratória e descritiva. Para a coleta de dados foram utilizadas como ferramentas entrevistas semiestruturadas e pesquisa documental, as quais foram tratadas por meio da técnica de análise de conteúdo. Os resultados apontam que as dificuldades apresentadas pelos campi estão relacionadas à energia, água e esgoto, coleta seletiva e deslocamento de pessoal e que essas dificuldades são bastante próximas entre os campi. Quanto às boas práticas, em todos os temas mínimos elas se fazem presentes, demonstrando que há ações sustentáveis efetivas na instituição que podem ser disseminadas.
\end{abstract}

Palavras-Chave: Plano de Logística Sustentável; Instituto Federal de Mato Grosso; Sustentabilidade; Administração Pública.

\section{Analysis of sustainability practices and rationalization of the use of materials and services on the IFMT campuses based on Sustainable Logistics Plans}

\begin{abstract}
:
In the preparation of the Sustainable Logistics Plan (PLS), among other rules established by normative instruction No. 10/2012, the minimum topics to be covered must be observed, so that they can guide sustainability practices and rationalization of the use of materials and services. In this sense, the objective of this paper is to identify and map the successful actions and the difficulties related to sustainability practices and rationalization of the use of materials and services on the campuses of the Federal Institute of Mato Grosso (IFMT in Portuguese), based on article 8 of normative instruction No. 10/2012. The research is classified as qualitative. As for the objectives, the research is exploratory and descriptive. For data collection, semi-structured interviews and documental research were used as tools, which were treated through the content analysis technique. The results show that the difficulties presented by the campuses are related to energy, water and sewage, selective collection and displacement of personnel, and that these difficulties are quite similar among the campuses. As for good practices, they are present in all the minimum themes, showing that there are effective sustainable actions in the institution that can be disseminated.
\end{abstract}

Keywords: Sustainable Logistic Plan; Federal Institute of Mato Grosso; Sustainability; Public Administration.

\begin{tabular}{c}
\hline $\begin{array}{l}\text { Universidade } \\
\text { Federal } \\
\text { Fluminense } \\
\text { R. Desembargador Ellis Hermydio Figueira, 783, Bloco A, sl. 218, Aterrado. } \\
27213-415 \text { - Volta Redonda, RJ - Brasil } \\
\text { www.uff.br }\end{array}$ \\
\hline $\begin{array}{c}\text { Copyright (C) 2022 RASI. Todos os direitos, até mesmo de tradução, são reservados. É } \\
\text { permitido citar parte de artigos sem autorização prévia, desde que seja identificada a fonte. }\end{array}$ \\
\hline
\end{tabular}


Análise das práticas de sustentabilidade e de racionalização do uso de materiais e serviços nos campi do IFMT a partir dos Planos de Logística Sustentável.

\section{Introdução}

A preocupação com as ações do homem no meio ambiente intensificou-se no século XX entre especialistas e governos, com proporções mundiais. A Organização das Nações Unidas $(\mathrm{ONU})$ tem tido papel importante nessa discussão, realizando nas últimas cinco décadas quatro conferências mundiais para tratar sobre o tema (Melo et al., 2012).

O Brasil, como país membro da ONU desde 1945, sendo um dos 51 países fundadores, esteve presente em todos esses encontros e, dessa forma, tem editado leis e decretos voltados à preservação do meio ambiente para que o país cumpra os compromissos firmados (Pott \& Estrela, 2017).

Buscando disseminar uma cultura de integração das políticas públicas e dar suporte aos gestores para desenvolver estratégias sustentáveis, o Governo Federal editou em 2012 o Decreto $\mathrm{n}^{\circ} 7.746$, que regulamenta o art. $3^{\circ}$ da Lei $\mathrm{n}^{\mathrm{o}} 8.666$, de 21 de junho de 1993 , e estabelece o Plano de Logística Sustentável (PLS) no âmbito federal (Luiz, 2014).

O PLS é uma consequência dos debates da Rio+20, onde foram reavaliados os compromissos firmados pela comunidade internacional na Rio 92, envolvendo temas relacionados aos desafios ambientais, sociais e econômicos (Pereira \& Barbosa, 2018).

O PLS é de caráter obrigatório para órgãos e entidades da Administração Pública Federal, foi regulamentado pela IN N ${ }^{\circ} 10 / 2012$ e pode ser considerado uma ferramenta de planejamento e gestão, com objetivos e responsabilidades definidos que busca induzir os órgãos e entidades públicas a estabelecerem práticas de sustentabilidade e racionalização de gastos nas atividades desenvolvidas (Luiz, 2014).

Por se tratar de uma autarquia federal, o Instituto Federal do Mato Grosso (IFMT), criado em 2008, através da Lei $\mathrm{n}^{\circ} 11.892$, também deve observar o que determina o Decreto $\mathrm{n}^{\circ}$ 7.746/2012 e utilizar PLS para estabelecer práticas sustentáveis em seus campi.

No art. $8^{\circ}$ da $\mathrm{IN} \mathrm{N}^{\circ} 10 / 2012$ são estabelecidos os temas mínimos que devem estar contidos nas práticas de sustentabilidade e racionalização do uso de materiais e serviços no Plano de Logística Sustentável. O atendimento aos temas mínimos previstos é de suma importância para que as práticas sustentáveis sejam efetivadas na instituição.

Diante do contexto narrado, surge o seguinte questionamento: Como os campi do IFMT têm atendido ao art. $8^{\circ}$ da IN $N^{\circ} 10 / 2012$ na elaboração e execução de seus PLS? Para responder à pergunta de pesquisa traçou-se como objetivo deste trabalho identificar e mapear as ações de sucesso e as barreiras relacionadas às práticas de sustentabilidade e de racionalização do uso de materiais e serviços nos campi do IFMT, a partir do art. $8^{\circ}$ da IN N ${ }^{\circ}$ $10 / 2012$.

Nesse sentido, pode-se afirmar que a importância deste estudo se concentra na perspectiva de contribuir com informações para subsidiar a adequação do PLS aos campi do Instituto Federal de Mato Grosso e, também, para a ampliação da prática de ações sustentáveis nos mesmos.

\section{Referencial Teórico}

\subsection{Ações do Estado com vistas à Sustentabilidade}

A preocupação com as consequências das ações do homem sobre o meio ambiente em nível global é relativamente recente. Ainda na década de 1960, acreditava-se que a poluição 
ambiental era um preço a ser pago pelo desenvolvimento econômico e, consequentemente, pela riqueza material, havendo dessa forma uma suposta troca entre o fator econômico e o fator ambiental (Oliveira, 2012).

No entanto, em função de uma série de desastres e desequilíbrios ambientais ocorridos, como as chuvas ácidas, a poluição do Mar Báltico, a acumulação de metais pesados e de pesticidas que impregnavam peixes e aves fez com que surgissem preocupações ambientais e protestos em prol do meio ambiente (Passos, 2009).

Diante dos apelos sociais, a Organização das Nações Unidas (ONU) buscou institucionalizar um movimento relacionado com as causas e os efeitos da poluição sobre o meio ambiente, e elevou a preocupação aos povos de todos os países (Silva, 1993), realizando nas últimas cinco décadas quatro conferências mundiais (Melo et al., 2012).

Concretizar os anseios das discussões sustentáveis na prática tem sido o grande desafio. Para que os esforços em prol do desenvolvimento sustentável sejam colocados em prática, o Estado tem papel crucial ao atuar como indutor de transformações econômicas, sociais, culturais e de comportamento, que podem multiplicar efeitos benéficos sobre a conservação e proteção do meio ambiente. A atuação do Estado é possível por meio da criação de políticas públicas de cunho ambiental, de leis ambientais, e ao conferir um viés ambiental em leis das mais diversas áreas (Costa et al., 2016).

O Brasil como país membro da ONU, desde 1945 e sendo um dos 51 países fundadores, esteve presente em todas as conferências sobre o Meio Ambiente e Desenvolvimento e, dessa forma, tem editado leis e decretos para que o país cumpra os compromissos firmados (Pott \& Estrela, 2017).

A título de exemplo cita-se a Constituição Federal, ao prever em seu art. 170, o princípio da ordem econômica fundamentando a defesa do meio ambiente e no art. 225, ao estabelecer que, todos têm direito ao meio ambiente equilibrado ecologicamente, bem de uso comum do povo e essencial à sadia qualidade de vida, impondo-se ao Poder Público e à coletividade o dever de defendê-lo e preservá-lo para as presentes e futuras gerações (Brasil, 1988).

Além da Constituição Federal, existem diversas outras leis que buscam a preservação ambiental. A fim de disseminar uma cultura de integração das políticas públicas e dar suporte aos gestores para desenvolver estratégias sustentáveis nos órgãos públicos como um todo, o Governo Federal editou, em 2012, o Decreto ${ }^{\circ} 7.746$, que regulamenta o art. $3^{\circ}$ da Lei $n^{\circ} 8.666$, de 21 de junho de 1993, e estabelece o Plano de Logística Sustentável (PLS) no âmbito federal (Luiz, 2014).

O Decreto $\mathrm{n}^{\circ} 7.746 / 2012$ abrange a administração pública federal direta, autárquica e fundacional e empresas estatais (Brasil, 2012a). Para regulamentar o decreto que instituiu o PLS, foi publicada a Instrução Normativa $N^{\circ}$ 10/2012 que dispõe sobre as regras para a elaboração do PLS.

A IN N ${ }^{\circ} 10 / 2012$ propõe que sejam observadas na elaboração do PLS iniciativas como, Programa de Eficiência do Gasto Público - PEG, Programa Nacional de Conservação de Energia Elétrica - Procel, Agenda Ambiental na Administração Pública - A3P, Coleta Seletiva Solidária, Projeto Esplanada Sustentável.

A IN N ${ }^{\circ} 10 / 2012$ estabelece, ainda, as regras que devem ser observadas para a elaboração do PLS, tais como, no art. $5^{\circ}$ o conteúdo mínimo, no art. $8^{\circ}$ os temas mínimos e no art. $9^{\circ}$ os tópicos para os planos de ação, bem como seus indicadores (Brasil, 2012b).

\subsection{Sustentabilidade em Instituições de Ensino}


Dentre os órgãos abarcados pelo Decreto $n^{\circ} 7.746 / 2012$ estão as Instituições Federais de Ensino. As Instituições de Ensino (IE), como um todo, têm um papel importante no desenvolvimento sustentável, a sua atuação deve ultrapassar o limite da preocupação em ensinar e formar alunos, mas também ter responsabilidade social ao capacitar pessoas conscientes da necessidade de garantir a sustentabilidade às gerações futuras (Vaz et al., 2010)

Segundo a Organização para a Cooperação e Desenvolvimento Econômico (OECD, 2010), as instituições de ensino superior (IES) são os principais impulsionadores do crescimento econômico e social por meio da criação de conhecimento (pesquisa), transferência conhecimento (ensino) e desenvolvimento comunitário (atividades de extensão).

Nesse sentido, são propostos dois desafios para às IE, o primeiro deles voltado para a perspectiva acadêmico-teórica e está relacionado à transmissão do conhecimento, formação de profissionais para dar respostas às questões nas várias esferas da vida em sociedade, conscientes de seus próprios impactos socioambientais. O segundo desafio está na atuação dos gestores na implantação de práticas de responsabilidade socioambiental, compreendendo as operações físicas e serviços oferecidos à comunidade interna e externa (Aglieri et al., 2009; Otero, 2010)

Para atender ao desafio teórico existem, no Brasil, documentações prescritivas, normas e legislações que norteiam as ações sobre o ensino da sustentabilidade nas IES, a começar pela Constituição Federal (CF), de 1988, que determina no inciso VI, $\S 1^{\circ}$ do artigo 225 , a promoção Educação Ambiental, pelo poder público, em todos os níveis de ensino (Brasil, 1988).

Outro instrumento legal voltado para o ensino da sustentabilidade é a Lei № 9.795, de 27 de abril de 1999, que dispõe especificamente sobre a Educação Ambiental e institui a Política Nacional de Educação Ambiental (PNEA) como componente essencial e permanente da educação nacional, devendo estar presente, de forma articulada, em todos os níveis e modalidades do processo educativo (Brasil, 1999).

Destaca-se, ainda, a Resolução $\mathrm{N}^{\circ} 02 / 2012 / \mathrm{CNE}$, que estabelece as Diretrizes Curriculares Nacionais para a Educação Ambiental, e tem como um de seus objetivos principais estimular a reflexão crítica e propositiva da inserção da Educação Ambiental na formulação, execução e avaliação dos projetos institucionais e pedagógicos das instituições de ensino, para que a concepção de Educação Ambiental como integrante do currículo não se restrinja à mera distribuição do tema pelos demais componentes (CNE, 2012).

Além das questões curriculares é primordial que as IES, diante da sua importância no direcionamento da humanidade, coloquem em prática aquilo que ensina, adotando em sua gestão e em seus espaços práticas sustentáveis para que se torne modelo para a sociedade onde estão inseridas (Pereira, 2017; Zagonel et al., 2019).

Embora não exista uma normativa própria, as instituições de ensino já vêm buscando há algum tempo, por conta própria e de maneira voluntária, desenvolver práticas sustentáveis em seus campi, como por exemplo, por meio do desenvolvimento de sistemas de gestão socioambiental, criação de agenda 21 própria (Barbieri \& Silva, 2011) e adesão a A3P (Araujo et al., 2017).

Apesar da existência de iniciativas, as Instituições de Ensino ainda carecem de maior atenção quanto ao desenvolvimento de práticas sustentáveis (Gazzoni et al., 2018), devido à complexidade de sua estrutura (Tauchen \& Brandli, 2006).

Contudo, apesar dos desafios, estudos de Corrêa et al. (2015) apontam que o Brasil tem sido um forte aliado da ONU na busca do fortalecimento de estratégias e ações para a sustentabilidade e inclusão da educação ambiental nas diretrizes curriculares de cursos de nível superior entre outros (Corrêa et al., 2015).

\section{Metodologia}


A pesquisa se classifica como de abordagem qualitativa, pois buscou conhecer a realidade investigada por meio de entrevistas com atores diretamente ligados ao objeto de estudo e por meio da pesquisa documental de registros relacionados com o objeto de estudo (Denzin \& Lincoln, 2006). Quanto aos objetivos, a pesquisa é classificada como exploratória e descritiva. Exploratória, pois buscou aumentar o conhecimento sobre o fenômeno pesquisado definindo o problema com mais precisão (Gil, 2005) e descritiva porque apresenta as principais dificuldades e boas práticas relacionadas às práticas de sustentabilidade e de racionalização do uso de materiais e serviços (Hair Jr. et al., 2005).

Para coleta de dados, os instrumentos de pesquisa escolhidos e utilizados foram entrevistas semiestruturadas, com perguntas elaboradas com base na IN $N^{\circ} 10 / 2012$, e pesquisa documental, tendo como fonte de dados os PLS publicados pelos campi, os relatórios semestrais e anuais e as atas de reunião das comissões.

O IFMT é formado por uma estrutura multicampi, atualmente, possuí quatorze campi, cinco campi avançados e a Reitoria. Embora o intuído da pesquisa fosse fazer um levantamento sobre o PLS em todos os campi da instituição, essa proposta não foi possível de ser atendida, pois para que o objetivo do trabalho fosse concretizado, seria necessário que os campi participantes já tivessem elaborado seu PLS e, especificamente, para a entrevista era necessário que o campus já estivesse com comissão responsável pelo PLS atuante há pelo menos um ano.

Nesse sentido, ao realizar levantamento entre os campi para verificar quais possuíam comissão, foi possível identificar e classificar as seguintes situações em relação às comissões responsáveis pelo PLS: "possui comissão em funcionamento" para os campi que responderam que havia comissão e que os membros estavam atuantes. "Não possui comissão" para os campi que responderam não haver comissão responsável pelo PLS no campus. "Comissão desatualizada" para os campi que responderam que a comissão havia sido designada, mas que por algum motivo os servidores já não estavam atuando na mesma.

E, por fim, "Comissão com menos de 01 ano", apesar de haver comissão, não havia nenhum membro da comissão anterior compondo a nova, além de os trabalhos da comissão anterior não ter sido dado continuidade após a publicação do PLS, dessa forma, os membros da nova comissão não teriam condições de responder às perguntas do roteiro de entrevista preparado previamente, para o qual seria necessário ter uma experiência de pelo menos um ano de acompanhamento do PLS.

Embora o decreto que estabelece o Plano de Logística Sustentável e a Instrução Normativa que o regulamenta terem sidos editados em 2012, verificou-se que, dos quatorze campi e dos cinco campi avançados do IFMT, apenas 09 (nove) possuíam comissão responsável pelo PLS atuante e aptas a prestar informações sobre as atividades desenvolvidas.

Dos nove campi com comissão atuante e, aptas a serem entrevistadas, apenas, 07 (sete) servidores presidentes de comissões pertencentes aos campi e campi avançados aceitaram participar da pesquisa.

Importante ressaltar que mesmo os campi que não possuíam comissão apta a prestar entrevista, conforme já esclarecido anteriormente, a análise dos PLS desses campi foi levada em consideração, pois poderiam contribuir com o levantamento dos dados da pesquisa.

Outra questão que ocorreu é que um dos campi que possui comissão em funcionamento não disponibilizou seu PLS, pois segundo informação do presidente da comissão, o mesmo estava em fase de reelaboração.

Para a pesquisa documental, os documentos analisados foram os PLS, os relatórios semestrais e anuais e as atas de reunião das comissões. Inicialmente foram feitas buscas pelo PLS e relatórios semestrais e anuais no site dos campi. Os PLS e relatórios não encontrados no 
site dos campi foram solicitados aos presidentes das comissões no momento das entrevistas. As atas das reuniões das comissões, também foram solicitadas aos presidentes no momento das entrevistas. Ao todo foram disponibilizados dez PLS, duas atas e dois relatórios anuais.

Com o intuito de identificar a origem das informações no momento da análise dos dados, mas cuidando para não expor os campi e os entrevistados a qualquer tipo de constrangimento, optou-se por substituir o nome dos entrevistados por siglas e renomear a origem dos documentos analisados, conforme Quadro 1.

Quadro 1. Codificação de documentos e entrevistados

\begin{tabular}{|c|c|}
\hline Documento & Código \\
\hline \multirow{10}{*}{ Plano de Logística Sustentável } & PLS campus $A$ \\
\hline & PLS campus $B$ \\
\hline & PLS campus $C$ \\
\hline & PLS campus $D$ \\
\hline & PLS campus $E$ \\
\hline & PLS campus $F$ \\
\hline & PLS campus $G$ \\
\hline & PLS campus $H$ \\
\hline & PLS campus $I$ \\
\hline & PLS campus $J$ \\
\hline \multirow{2}{*}{ Relatório } & RLT campus $B$ \\
\hline & RLT campus $F$ \\
\hline \multirow{2}{*}{ Ata reunião comissão } & ATA campus $F$ \\
\hline & ATA campus $G$ \\
\hline Entrevistado & Código \\
\hline \multirow{7}{*}{ Presidentes de comissão nos campi } & E campus F \\
\hline & E campus B \\
\hline & E campus $\mathrm{K}$ \\
\hline & E campus $\mathrm{C}$ \\
\hline & E campus $\mathrm{G}$ \\
\hline & E campus $\mathrm{E}$ \\
\hline & E campus $\mathrm{A}$ \\
\hline
\end{tabular}

Fonte: Elaboração própria (2021).

As entrevistas e os documentos foram analisados e tratados de modo qualitativo por meio da técnica de análise de conteúdo. Para realizar a análise de conteúdo foram utilizados os passos que seguem a estrutura proposta por Bardin (1977), que consistem na pré-análise; exploração do material e tratamento dos resultados, inferência e interpretação.

A pesquisa levou em consideração todos os campi da instituição que possuíam PLS publicado no site institucional, bem como os campi que alegaram possuir comissão responsável pelo PLS atuante. Ao analisar previamente os PLS, verificou-se que nem todos os campi observaram os temas mínimos a serem abrangidos, conforme estabelece o art. $8^{\circ}$ da IN $\mathrm{N}^{\mathrm{o}}$ 10/2012, nesse sentido, surgiu a indagação de que poderiam haver barreiras para que todos os temas fossem abordados.

Portanto, o objetivo da análise dos dados foi entender em quais temas os campi estavam tendo dificuldades para propor ações sustentáveis e quais as possíveis origens dessas dificuldades, como também identificar as ações de sucesso que já são praticadas nos campi, para que essas pudessem ser compartilhadas com os demais.

Na presente pesquisa, os documentos submetidos à análise foram constituídos por dados primários, obtidos nas entrevistas semiestruturadas, e dados secundários, composto pelos PLS, relatórios anuais e as atas das reuniões das comissões disponibilizadas pelos campi. 
Para se chegar à etapa da inferência e posterior análise (interpretação), foram propostas categorias analíticas. As categorias analíticas foram baseadas a partir dos temas mínimos previstos no art. $8^{\circ}$ da IN $N^{\circ} 10 / 2012$, a saber, material de consumo; energia elétrica; água e esgoto, coleta seletiva; qualidade de vida; compras e contratações sustentáveis; deslocamento de pessoal.

\section{Resultados}

A análise dos resultados será apresentada de modo que responda ao objetivo da pesquisa, a saber, identificar e mapear as ações de sucesso e as dificuldades relacionadas às práticas de sustentabilidade e de racionalização do uso de materiais e serviços nos campi do IFMT.

Antes de discorrer sobre a análise e discussão dos resultados, ressalta-se que as decisões administrativas para todas as sete categorias de análise são descentralizadas da Reitoria, ou seja, cada campus tem autonomia para decidir individualmente, cabendo à Reitoria prestar auxílio e orientação sobre as melhores práticas as serem adotada.

A partir da análise prévia dos PLS, verificou-se que, dentre os temas mínimos previstos na IN $N^{0} 10 / 2012$, apenas os temas água e esgoto foram tratados por todos os campi da instituição, conforme Quadro 2.

Quadro 2. Levantamento dos temas mínimos nos PLS

\begin{tabular}{|l|c|}
\hline \multicolumn{1}{|c|}{ Temas Mínimos a Serem Abrangidos } & Quant. atendeu ao requisito \\
\hline $\begin{array}{l}\text { Material de consumo (no mínimo papel para impressão, copos } \\
\text { descartáveis e cartuchos para impressão). }\end{array}$ & 7 \\
\hline Energia elétrica. & 9 \\
\hline Água e esgoto. & 9 \\
\hline Coleta seletiva & 8 \\
\hline Qualidade de vida no ambiente de trabalho. & 9 \\
\hline $\begin{array}{l}\text { Compras e contratações sustentáveis (pelo menos, obras, equipamentos, } \\
\text { serviços de vigilância, de limpeza, de telefonia, de processamento de } \\
\text { dados, de apoio administrativo e de manutenção predial). }\end{array}$ & 8 \\
\hline $\begin{array}{l}\text { Deslocamento de pessoal, considerando todos os meios de transporte, com } \\
\text { foco na redução de gastos e de emissões de substâncias poluentes. }\end{array}$ & \\
\hline
\end{tabular}

Fonte: Elaboração própria (2021), com base no art. $8^{\circ}$ da IN $\mathrm{N}^{\circ} 10 / 2012$.

Pode ser observado que os temas atendidos por, praticamente, todos os campi que possuem PLS, entre nove e dez campi, são, energia elétrica, água e esgoto, coleta seletiva e compras e contratações sustentáveis, esses resultados são próximos aos apontados por estudo realizado em universidades da Malásia, onde foram identificadas como tendo prioridades mais altas no gerenciamento de suas instalações iniciativas para eficiência energética, redução de resíduos e conservação da água (Hasim et al., 2020).

A análise do atendimento aos temas mínimos foi triangulada com as entrevistas, as atas de reuniões e os relatórios anuais apresentados pelos campi. A seguir será apresentado, detalhadamente, cada um dos temas mínimos exigidos de acordo com o art. $8^{\circ}$ da $\mathrm{IN} \mathrm{N}^{\circ}$ 10/2012, na ordem dos incisos I à VII.

No que tange ao tema "Material de consumo" em que é sugerido no mínimo papel para impressão, copos descartáveis e cartuchos para impressão percebe-se que dentre os campi essa prática tem se mostrado efetiva.

“A questão do aproveitamento do papel, rascunho [...], então a conscientização do rascunho, hoje a gente já conseguiu com que a maioria dos setores faça, imprimam, 
praticamente tudo na parte do rascunho, só documento oficial que não tem como, né? A pessoa não precisa usar o rascunho. $\mathrm{O}$ copo eu acho que foi um grande avanço, eu vou falar pelo meu setor, hoje a gente não utiliza copo plástico, dificilmente, hoje cada um tem o seu copo de vidro, né? Ah, outra coisa que nós usávamos era tonner, ave Maria, era recorde, hoje já diminuiu muito [...]” (E campus C).

"Fornecimento de canecas, copos para servidores, estagiários e terceirizados. Para os alunos foram fornecidas garrafas tipo squeezes" (RLT campus $F$ ).

As ações desenvolvidas pelos campi do IFMT relacionadas ao tema "material de consumo" são bem próximas às apresentadas em outras instituições de ensino como o CEFET/RJ, que realiza a impressão de documentos no modo frente e verso (Trigo et al., 2014) e o IFRN, que tem reduzido o uso de copos plásticos descartáveis a partir da utilização de canecas e squeezes (Silva \& Pinheiro, 2018).

Quanto ao tema "Energia elétrica" percebe-se que os campi do IFMT têm buscado formas de reduzir o consumo.

\footnotetext{
“[...] em todas as salas têm uns "adesivinhos" falando 'desligue ao sair' 'desligue o ar condicionado', 'desligue as luzes', então são práticas bacanas que a ajudam a reduzir o gasto energético dentro do campus" (E campus E).

[...] criando cortina verde pra diminuir o uso de ar condicionado que é uma coisa de longo prazo $[\ldots]$ (E campus $\mathrm{G})$.

"[...] a questão da energia, a gente trocou vários ares por daqueles lá... deixa eu lembrar o nome...[...] Inverter, né? [...] Questão de desligar, questão de finais de semana desligar os bebedouros, desligar também os computadores. A gente até começou de uns tempos pra cá programar para que os computadores desliguem depois de um certo horário, depois das nove e meia, acho que foi esse horário mesmo, nove e meia, todos os computadores do campus já desligam, né? Pra não ter esse problema. Porque, as vezes, acontece do servidor deixar ele ligado" (E campus C).
}

As práticas relacionadas à energia elétrica podem partir de iniciativas simples, como a conscientização sobre não deixar aparelhos ligados quando esses não estiverem sendo utilizado, quanto à revisão das demandas de energia elétrica. Ambas são ações que não demandam investimentos, ao contrário, reduzem custos e proporcionam resultados efetivos na instituição (Trigo et al., 2014).

Apesar das boas práticas mencionadas, ainda existem na instituição resistência ao desenvolvimento de atividades rotineiras que visam à racionalização desse recurso (Gazzoni et al., 2018), conforme relatado no PLS do campus $A$ "constante ocorrência de lâmpadas e equipamentos (computadores e aparelhos de ares-condicionados principalmente) ligados, porém sem presença e/ou uso por usuários".

Outra iniciativa relacionada à questão da energia elétrica é a implantação de usinas fotovoltaica nos campi, que se apresenta como uma ação concreta em torno de uma possível política de desenvolvimento sustentável na instituição.

\footnotetext{
"É.. nós temos, ainda, nossa estação, estação fotovoltaica. Já foi implantada aqui. Ela é utilizada, apesar de ser um recurso tecnológico, até porque nós termos um curso em eletrotécnica industrial aqui, mas não deixa de ser uma prática sustentável ao produzir energia solar" (E campus E).

"Estamos aí na luta pra fazer com que o estacionamento que nós não temos coberto, seja feito com as placas [solares] em cima. Vamos ver se essa ideia consegue sair aí futuramente. [...]" (E campus C).
} 
Embora a implantação de usinas fotovoltaicas exija um valor considerável no orçamento da instituição, deve ser considerada como um investimento à longo prazo, em que o valor investido retornará ao campus, na forma de desconto na conta de energia a partir da sua geração própria.

"Água e Esgoto": o uso racional da água é o tema mínimo tratado por todos os campi que possuem PLS publicado, demonstrando a preocupação com o uso adequado desse recurso. A maioria das ações previstas nos PLS está relacionada à conscientização e implantação de dispositivos que auxiliam na economia de consumo.

Desde 2015 o Projeto Esplanada Sustentável, através da portaria $\mathrm{N}^{\circ} 23$, tornou obrigatório para todas as unidades da Administração Pública federal direta, autárquica e fundacional o acompanhamento do consumo da água através do Sistema Esplanada Sustentável (SisPES), que visa auxiliar no controle das despesas administrativas, avaliando em que medidas as ações adotadas pela Administração Pública na redução do consumo de papel, energia elétrica e água atingiram os objetivos propostos (Brasil, 2015).

No entanto, não são todos os campi que realizam o acompanhamento do consumo de água, devido à água utilizada nesses campi ser oriunda de poços artesianos.

\begin{abstract}
"Não foi possível tabular o consumo de água do IFMT [nome do campus] até o momento, pois este não recebe água da rede de fornecimento, utilizando assim água de poço" (PLS campus $C$ ).

"Em relação à água, a água, por exemplo, nós aqui não utilizamos da cidade, nós temos poços artesianos, eles carecem de regulamentação, por conta do uso, eu acho que em nenhum lugar dentro da instituição IFMT já regulamentou poços, é uma coisa que mais cedo ou mais tarde vai ter que acontecer. [...]. Entretanto, nós precisávamos, até é uma das nossas restrições é essa, fazer a mensuração, precisávamos de registros, colocar esses registros em alguns lugares específicos, trabalhar com essa mensuração" (E campus K).
\end{abstract}

Nesse sentido, faz-se necessário nos campi do IFMT que possuem poços artesianos, a implantação de registros que possibilitem a mensuração do consumo de água, a fim de conhecêlo e controlá-lo. Uma iniciativa que merece destaque é a realizada pelo campus $D$ que criou Comissão de Estudos e Propostas para Consumo Racional de Água, com intuito de se avaliar o padrão de consumo de água do Campus e propor medidas para o uso racional (PLS campus $D$ ).

Os campi têm demonstrado maior dificuldade com o esgoto, tanto em relação a questões internas, quanto externas à instituição. Quanto às questões internas, alguns campi possuem estruturas muito antigas, que demandam adequações que requerem investimento. O esgoto pode ser considerado o tema mínimo que demanda maior investimento para ser atendido.

Em relação às questões externas dependendo de sua localização os campi não têm acesso à rede de coleta e tratamento de esgoto. Apesar de não ter sido feito um levantamento mais detalhado dessa situação no âmbito de cada campus, verificou-se que ambas existem na instituição.

"[...] Igual, hoje a gente não tem uma estação de tratamento de esgoto, nosso esgoto não é tratado, vem uma empresa lá e coleta, né? Fossa. A gente queria comprar uma rede de tratamento que tem pequena que dá pra comprar, só que hoje a gente não tem o dinheiro" (E campus C).

"Além disso, o município possui ausência de aterro sanitário e déficits na implantação de rede de esgoto. O campus não possui coleta por uma rede de esgoto. Os descartes são conduzidos para fossas sépticas localizadas ao lado do pavilhão administrativo" (PLS campus $E$ ). 
As ações que buscam implantar a Coleta seletiva nos campi têm-se mostrado bastante presente, como pode ser observado nas entrevistas, nos PLS e nos relatórios elaborados pelos campi.

\footnotetext{
“É... a questão da ... do... descarte do papelão e do tonner, a gente conseguiu, eu também achei que foi bacana. [...] conseguimos fazer, e a produção do sabão para a limpeza do instituto e do campus, né? Aqui do campus" (E campus F).

"[...] coletas seletivas de resíduos [...] foram instalados pontos de coletas de pilhas na sala dos professores em parceria com a UFMT [...]" (Relatório campus $B$ ).

"Recolhimento de tonners, cartuchos e materiais de informática, com encaminhamento às cooperativas de reciclagem [...]" (PLS campus $H$ ).
}

No entanto, ainda existem dificuldades internas e externas de tornar a coleta seletiva efetiva nos campi. Em relação às dificuldades internas, podem ser superadas (Dotto et al., 2019) por meio de iniciativas e ações desenvolvidas pela comunidade acadêmica, constituída de alunos, professores e funcionários (Marques et al.; Warken et al., 2014), com projetos, campanhas de sensibilização e a orientação dos terceirizados no recolhimento do lixo (Trigo et al., 2014).

No que tange aos obstáculos externos que impossibilitam ou dificultam a destinação dos resíduos gerados estão relacionados a logística para o descarte do material e a ausência de locais adequados nos municípios para sua destinação. Essa dificuldade é percebida em diferentes cidades do estado de Mato Grosso onde os campi do Instituto Federal estão inseridos, até mesmo na capital do estado e arredores.

\footnotetext{
"Não existe empresa específica para reutilização e reciclagem de resíduos eletrônicos [...]" (Relatório campus $F$ ).

"Existem dificuldades relacionadas com a coleta seletiva, o município não possui um plano de logística para descarte dos resíduos separados no IFMT - (nome do campus), também há uma dificuldade no descarte dos lixos eletrônico" (Relatório campus $B$ ). "[...], todavia encontra dificuldades no que tange a destinação às Associações Cooperativas de Catadores, tendo em vista, que as três cooperativas existentes no município [...] não se interessaram pela parceira, devido ao pouco volume de resíduos recicláveis produzidos pela Instituição" (PLS campus $D$ ).
}

O tema Qualidade de Vida no Ambiente de Trabalho (QVAT) começou a ser discutido na década de 1990 nas Conferências Mundiais sobre Desenvolvimento Sustentável (DS) e passou a ser utilizado pelo governo federal brasileiro, a partir da A3P (Nogueira et al., 2019).

A promoção da qualidade de vida é considerada uma forma de a Administração Pública promover a satisfação das necessidades dos servidores durante as atividades laborais através de ações que proporcionem melhorias no ambiente de trabalho, promoção da saúde e segurança e desenvolvimento das capacidades humanas (Gazzoni et al., 2018).

As atividades que podem ser realizadas dentro do tema qualidade de vida são bastante amplas e diversificadas, tais como, aproveitamento das habilidades e autonomia na atividade desenvolvida, criação de áreas comuns para integração de servidores, promoção dos relacionamentos interpessoais, ginástica laboral, salubridade dos ambientes, comissões internas de saúde do servidor público, observação e controle da jornada de trabalho, carga horária e condições adequadas, além de plano de cargos e salários que remunera e valoriza tempo de atuação, titulação e produção científica (Gazzoni et al., 2018; Kruger et al., 2011; Silva \& Pinheiro, 2018). 
Dentre as atividades acima citadas, algumas puderam ser observadas no relato dos entrevistados, bem como nas atas e nos planos em si.

\begin{abstract}
"E... também... a gente tem a questão da qualidade vida, que é uma das metas do PLS, é... nós fizemos algumas ações com o núcleo de qualidade de vida que foi essa feira solidária e também a gente fez algumas palestras sobre prevenção do câncer de mama, nós convidamos uma enfermeira e a gente fez em conjunto, uma ação conjunta da sustentabilidade e da qualidade de vida e, fizemos algumas ações nessa questão de assédio moral, de tratamento, [...], conseguimos um lugar melhor pra fazer a sala de convivência para os servidores. E ... integração foi feito caminhada ecológica no horto, né? Que a gente organizou caminhada para alguns servidores e para integração, né? O núcleo de qualidade de vida tá trabalhando bem essa questão[...]” (E campus F).

"[...] Realização do evento denominado "10 Semana de Prevenção e Saúde do Trabalhador do IFMT (nome do Campus)" previsto para o próximo semestre e também para diagnóstico de riscos posturais e semana de prevenção de acidentes" (Ata campus $G$ ).

"Foi construído uma área de convivência no acesso ao refeitório, com bangalôs, mesas e bancos de madeira e com acesso à rede elétrica, internet e wi-fi. Foram disponibilizados bancos confeccionados em material reciclado nos principais corredores e hall de entrada do Campus" (PLS campus A).
\end{abstract}

Pelo fato de o tema qualidade de vida ser bastante amplo e proporcionar uma gama de possibilidades de trabalho, a comissão responsável pelo PLS pode descentralizar a responsabilidade e trabalhar em parceria com o núcleo de qualidade de vida, que são comissões responsáveis pelo tema que já existiam nos campi antes mesmo de ser tratado no PLS (Nogueira et al., 2019).

As compras e contratações sustentáveis preocupam-se com as questões ambientais no momento de adquirir produtos, buscando alcançar um processo menos agressivo ao meio ambiente (Warken et al., 2014), essa maneira de contratação já vêm sendo adotada pelo IFMT antes de ser instituído o PLS, pois em 2010 foram editadas a IN $\mathrm{N}^{\circ} 01$, que inseriu critérios ambientais nas licitações públicas brasileiras, e a Lei $\mathrm{n}^{0} 12.349$, que institui normas para licitações e contratos da Administração Pública (Teixeira \& Azevedo, 2013), sendo ambas observadas no âmbito da instituição.

\footnotetext{
"O setor de gestão de contratos já trabalha [...] já trabalha com contratações sustentáveis, né?” (E campus F).

"Aí questão de compra de papel também já assim... todos os processos, na verdade, todos os nossos processos de licitação já têm essa questão da sustentabilidade, né? Por exemplo, compra de papel, papel livre de cloro é... Então já tem alguma coisa, assim mais institucionalizado, tá? Já tem essas ações" (E campus B).
}

Por fim, verificou-se sobre o tema deslocamento de pessoal. Embora existam ações previstas sobre o tema deslocamento de pessoal no PLS dos campi, percebe-se que carecem de maior estudo de viabilidade para que se tornem efetivas. Muitas vezes a otimização nos deslocamentos acabam esbarrando em situações que impedem sua efetivação, conforme relatado no relatório do campus $F$ "A utilização de carona compartilhada entre os campi é inviável devido à localização geográfica de (nome da cidade onde o campus está localizado)" e "A realização de videoconferência depende da qualidade da internet" (RLT campus F).

Uma alternativa para a questão da otimização em relação ao deslocamento de pessoal sugerida por um dos campi da UFABC apresentada através dos estudos de Pereira e Barbosa, 
(2018, p. 22) foi a "parceria com uma ONG para desenvolver alternativas sustentáveis de mobilidade de sua comunidade acadêmica, na busca de soluções integradas com o poder público local". Outra solução apresentada foi a prevista no relatório do campus $B$, o qual sugere a "Carona Solidária" entre os servidores através de aplicativo de mensagens.

Além dos temas mínimos exigidos, destacou-se durante as entrevistas e a análise dos PLS, uma ação que permeia vários dos temas do PLS e que é a adotado por vários campi: a arborização.

A arborização desempenha funções múltiplas como a melhora do conforto térmico, contribuindo para a redução da necessidade de climatização nos ambientes, controla a poluição atmosférica sonora e aumenta a drenagem do solo e, consequentemente, proporciona melhor qualidade de vida na instituição (Silva \& Pinheiro, 2018) e surge como uma alternativa de baixo custo, inclusive ser desenvolvida através de projetos de pesquisa, e que pode ser adotada por todos os campi de acordo com sua realidade.

No Quadro 3 é apresentada uma síntese das ações de sucesso e das dificuldades relacionadas às práticas de sustentabilidade e de racionalização do uso de materiais e serviços nos campido IFMT identificadas e mapeadas utilizando-se como base os temas mínimos previstos no art. $8^{\circ}$ da IN N $10 / 2012$.

Quadro 3. Síntese da análise e discussão dos resultados

\begin{tabular}{|c|c|c|}
\hline Tema & Ações de sucesso & Dificuldades \\
\hline $\begin{array}{l}\text { Material de } \\
\text { Consumo }\end{array}$ & $\begin{array}{l}\text { Substituição do uso de copos descartáveis por } \\
\text { reutilizáveis; } \\
\text { Aquisição de impressoras para impressão frente e } \\
\text { verso; } \\
\text { Adesão à impressão em rascunho de documentos não } \\
\text { oficiais; } \\
\text { Impressão no modo rascunho para economizar tonner }\end{array}$ & Não houve relatos. \\
\hline $\begin{array}{l}\text { Energia } \\
\text { Elétrica }\end{array}$ & $\begin{array}{l}\text { Implantação de avisos para conscientização sobre o } \\
\text { consumo de energia elétrica; } \\
\text { Aquisição e implantação de usinas fotovoltaicas; } \\
\text { Arborização; }\end{array}$ & $\begin{array}{l}\text { Presença de lâmpadas e equipamentos } \\
\text { ligados sem a presença de usuários. }\end{array}$ \\
\hline $\begin{array}{l}\text { Água e } \\
\text { Esgoto }\end{array}$ & $\begin{array}{l}\text { Aquisição e implantação de equipamentos que } \\
\text { auxiliam na economia de consumo } \\
\text { Criação de Comissão de Estudos e Propostas para } \\
\text { Consumo Racional de Água. }\end{array}$ & $\begin{array}{l}\text { Dificuldades na mensuração e, } \\
\text { consequentemente, no controle do } \\
\text { consumo de água nos campi que } \\
\text { possuem poços artesianos. } \\
\text { Ausência de rede esgoto municipal } \\
\text { onde os campi estão localizados. } \\
\text { Necessidade de adequação das } \\
\text { estruturas internas para coleta e } \\
\text { tratamento de esgoto. }\end{array}$ \\
\hline $\begin{array}{l}\text { Coleta } \\
\text { Seletiva }\end{array}$ & $\begin{array}{l}\text { Implantação de lixeiras para coleta seletiva. } \\
\text { Rotinas de separação e destinação de material } \\
\text { reciclável. }\end{array}$ & $\begin{array}{l}\text { Não atendimento dos usuários quanto } \\
\text { a separação dos resíduos nos } \\
\text { recipientes adequados. } \\
\text { Inexistência, nos municípios onde os } \\
\text { campi estão inseridos, de locais para } \\
\text { destinação ou recolhimento dos } \\
\text { resíduos gerados. }\end{array}$ \\
\hline $\begin{array}{l}\text { Qualidade de } \\
\text { vida }\end{array}$ & $\begin{array}{l}\text { Palestras sobre temas relevantes; } \\
\text { Área de convivência para servidores; } \\
\text { Momentos de integração; } \\
\text { Arborização }\end{array}$ & Não houve relatos. \\
\hline \multicolumn{3}{|c|}{ uadro 3. Síntese da análise e discussão dos resultados (continuação) } \\
\hline
\end{tabular}




\begin{tabular}{|c|c|c|}
\hline Tema & Tema & Tema \\
\hline $\begin{array}{l}\text { Compras e } \\
\text { contratações } \\
\text { sustentáveis }\end{array}$ & $\begin{array}{l}\text { Os processos de aquisições e contratações no âmbito } \\
\text { do IFMT já utilizam os critérios ambientais exigidos } \\
\text { para as contratações públicas; }\end{array}$ & Não houve relatos. \\
\hline $\begin{array}{l}\text { Deslocamento } \\
\text { de Pessoal }\end{array}$ & $\begin{array}{l}\text { Iniciativas de carona solidária; } \\
\text { Substituição de reuniões presenciais por } \\
\text { videoconferências; } \\
\text { Planejamento dos deslocamentos para otimização das } \\
\text { atividades realizadas no mesmo percurso. }\end{array}$ & $\begin{array}{l}\text { Necessidade de maiores estudos de } \\
\text { viabilidade de deslocamento de } \\
\text { pessoal para que se tornem efetivas. }\end{array}$ \\
\hline
\end{tabular}

Fonte: Elaboração própria (2021), com base na análise e discussão dos resultados.

\section{Considerações Finais}

A Instrução Normativa $\mathrm{N}^{\circ}$ 10/2012, que regulamenta o decreto $\mathrm{N}^{\circ}$ 7.746/2012, estabelece em seu art. $8^{\circ}$ os temas mínimos que devem estar contidos nas práticas de sustentabilidade e racionalização do uso de materiais e serviços no Plano de Logística Sustentável.

Apresentam-se, desta maneira, as principais dificuldades relacionadas às práticas de sustentabilidade e de racionalização do uso de materiais e serviços no PLS dos campi e, na sequência, as boas práticas que também se fazem presentes.

Identificam-se, portanto, dificuldades à adesão dos usuários às práticas de racionalização do consumo de energia elétrica; ao fazer o controle e racionamento do consumo de água nos campi que possuem poços artesianos; para atender e propor ações a questões inerentes ao esgoto; para utilizar corretamente as lixeiras de coleta seletiva e destinar os resíduos gerados para cooperativas de reciclagem; para viabilizar práticas deslocamento de pessoal efetivas nos campi e na instituição.

Embora a maioria das dificuldades estejam relacionadas à questões internas, os campi também esbarram em situações externas que prejudicam a efetivação de suas práticas sustentáveis, como é o caso da inexistência de rede de coleta e tratamento de esgoto; inexistência de cooperativas de reciclagem na região onde estão inseridos ou falta de interesse das cooperativas em recolher dos resíduos gerados pelos campi; no tema deslocamento de pessoal percebeu-se poucas iniciativas relacionadas, indicando a necessidade de maiores estudos de viabilidade de deslocamento de pessoal para que se tornem efetivas nos campi e na instituição.

Quanto às boas práticas presentes nos campi, foram identificadas as seguintes: no tema material de consumo foi observado que os campi têm se atentado para esses requisitos e os atendidos. As principais ações estão em torno de campanhas para substituir os copos descartáveis por copos reutilizáveis, canecas, squeezes e conscientização sobre o consumo de papel e tonner.

O consumo de energia é um dos temas que também apresenta uma série de ações de sucesso, como implantação de aviso sobre o consumo consciente, a instalação de usinas fotovoltaicas nos campi da instituição e aquisição e substituição de equipamentos com menor consumo energético.

A água foi o tema que todos os campi abordaram durante a elaboração do PLS, demonstrando a preocupação com a utilização e, consequentemente, a preservação desse recurso.

O tema qualidade de vida, por se tratar de um tema bastante amplo, possui ações desde palestra de conscientização sobre o risco de determinadas doenças relacionadas ou não ao trabalho, direitos e deveres dos servidores, ética no ambiente de trabalho, momentos de 
integração e confraternização, disponibilização de locais para área de convivência, entre outras. Muitos campi da instituição possuem comissões específicas para tratar sobre esse assunto, podendo as ações da comissão do PLS ser integrada a elas.

A coleta seletiva é um tema que tem se destacado dentro da instituição, os campi têm demonstrado sua preocupação em relação a esse tema realizando aquisição/confecção de lixeiras para a adequada destinação dos resíduos sólidos gerados, além de campanhas e projetos de conscientização sobre o correto descarte entre a comunidade acadêmica, tanto em relação aos alunos, servidores e terceirizados.

As compras sustentáveis traduzem-se como uma ação que vem sendo observada pela instituição como um todo, antes mesmo da previsão no PLS, pois já visava atender a IN $\mathrm{N}^{\circ}$ 01/2010 e a Lei $\mathrm{n}^{\circ}$ 12.349/2010, que instituíram critérios sustentáveis para licitações e contratos da Administração Pública, sendo atendidas em todos os editais para compra e prestação de serviços da instituição.

No tema deslocamento de pessoal, verificou-se que os campi previram ações voltadas à otimização das viagens, adequando o trajeto a ser percorrido, bem como realizando o maior número de atividades possíveis em um único deslocamento. Outra questão que surgiu no tema que não está diretamente ligada ao uso de recursos da instituição, mas que pode ser fomentada para trazer benefícios à comunidade, é a implantação da carona solidária.

A arborização foi uma ação que permeou vários temas abordados, diversos campi citaram que essa ação vem sendo desenvolvida e que traz inúmeros benefícios, tais como, diminui a temperatura dos ambientes, fazendo com que se utilize menos o ar-condicionado, consequentemente, diminuem o consumo de energia elétrica. Os espaços arborizados propõem, ainda, a melhoria da qualidade de vida, ao servirem de locais para descanso, além de reduzirem a poluição atmosférica.

Diante dos resultados apresentados conclui-se que as dificuldades apresentadas pelos campi estão relacionadas à energia, água e esgoto, coleta seletiva e deslocamento de pessoal e que essas dificuldades são bastante próximas entre os campi, portanto, a busca por uma solução em conjunto poderia resolver a situação de todos. Não houve relatos de dificuldades em relação aos temas material de consumo, qualidade de vida e compras e contratações sustentáveis.

Quanto às boas práticas, em todos os temas mínimos elas se fazem presentes, demonstrando que há ações efetivas na instituição, no entanto, se faz necessário o apoio institucional para que essas sejam intensificadas e disseminadas entre todos os campi, inclusive naqueles que ainda não implantaram o PLS.

Entre as contribuições que este trabalho apresenta está a contribuição para o IFMT, ao traçar um panorama geral da atual situação das práticas sustentáveis bem-sucedidas e das limitações das mesmas, possibilitando aos gestores tomarem conhecimento para futuras ações.

Citam-se, ainda, as contribuições para o meio ambiente, pois ao efetivar o PLS na instituição, além de proporcionar práticas sustentáveis locais, também poderá contribuir com a formação acadêmica dos discentes, ao formar cidadãos conscientes de suas ações no meio ambiente, com o intuito de que sejam replicadores dessas boas práticas. Nesse sentido, a contribuição além de local também tem possibilidade de se tornar global.

As limitações da pesquisa ficaram da impossibilidade de entrevistar todos os presidentes de campi que possuem comissão em funcionamento, devido à sua negativa à entrevista, bem como a não disponibilização das atas que os entrevistados disseram possuir, porém que acabaram não sendo disponibilizadas. 
Fica como sugestão para estudos futuros, a análise completa dos conteúdos mínimos exigidos no PLS, bem como a proposição de ações para que as dificuldades na execução do PLS sejam superadas.

\section{Referências Bibliográficas}

Aglieri, L., Aglieri, L. A., \& Krugianskas, I. K. (2009). Gestão Socioambiental: Responsabilidade e Sustentabilidade do Negócio. Editora Atlas.

Araujo, S. M. D., Freitas, L. S., \& Rocha, V. S. G. (2017). Gestão Ambiental: Práticas Sustentáveis nos Campi de uma IFES. Revista de Administração Contabilidade e Sustentabilidade (REUNIR), 7(3), 36-50. https://doi.org/10.18696/reunir.v7i3.672

Barbieri, J. C., \& Silva, D. (2011). Desenvolvimento Sustentável e Educação Ambiental: Uma Trajetória comum com muitos Desafios. Revista de Administração Mackenzie (RAM), 12(3), 51-82. https://doi.org/10.1590/s1678-69712011000300004

Bardin, L. (1977). Análise de Conteúdo. Editora Persona, 70ª edição.

Brasil. (1988). Constituição Federal.

Brasil. (1999). Lei no 9.795, de 27 de Abril de 1999. http://www.planalto.gov.br/ccivil_03/LEIS/L9795.htm

Brasil. (2012a). Decreto $n^{\circ}$ 7.746/2012.

Brasil. (2012b). IN $n^{\circ}$ 10/2012.

Brasil. (2015). Portaria $n^{\circ}$ 23/2015.

CNE. (2012). Resolução $n^{\circ}$ 2/2012.

Corrêa, A. C., Ávila, L. V., Schuch Jr., V. F., Madruga, L. R. D. R. G., Hoffmann, C., \& Erdmann, R. H. (2015). Sustentabilidade das Políticas e Estratégias para a Educação Superior no Brasil: Uma Análise sob a Ótica da Teoria dos Sistemas Autopoiéticos. Revista Gestão Universitária na América Latina (GUAL), 153-176. https://doi.org/10.5007/1983$4535.2015 \mathrm{v} 8 \mathrm{n} 2 \mathrm{p} 153$

Denzin, N. K., \& Lincoln, Y. S. (2006). O Planejamento da Pesquisa Qualitativa: Teorias e Abordagens. Editora Artmed.

Dotto, M. D. R., Feltrin, T. S., Denardin, A. C. M., \& Ruiz, L. de M. (2019). Sustentabilidade em Organizações Públicas: Estudo de uma Instituição Federal de Ensino Brasileira Sostenibil. Revista de Gestão Ambiental e Sustentabilidade (GEAS), 8(2), 235-259.

Costa, C. F., Diniz, M. F. S., Cunha, N. R. S., \& Pires, R. R. (2016). O Fator Sustentabilidade nas Licitações e Contratações Públicas. Reuna, 21(4), 37-56. https://doi.org/10.21714/2179-8834/2016v21n4p37-56

Gazzoni, F., Scherer, F. L., Hahn, I. S., Carpes, A. M., \& Santos, M. B. (2018). O Papel das IES no Desenvolvimento Sustentável: Estudo de Caso da Universidade Federal de Santa Maria. Revista Gestão Universitária $\mathrm{Na}$ América Latina (GUAL), 48-70. https://doi.org/10.5007/1983-4535.2018v11n1p48

Gil, A. C. (2005). Métodos e Técnicas de Pesquisa Social. Editora Atlas, $5^{\text {a }}$ edição.

Hair Junior., J. F., Babin, B., Money, A. H., \& Samouel, P. (2005). Fundamentos de 
Métodos de Pesquisa em Administração. Editora Bookman.

Hasim, M. S., Abdullah, A. S., Rasam, A. R. A., \& Ismail, H. (2020). The Adoption of Sustainable Facilities Management Practices in Organisations: A Study of Malaysian Universities. Environment-Behaviour Proceedings Journal, 5(13), 299. https://doi.org/10.21834/e-bpj.v5i13.1898

Kruger, S. D., Dahmer, E. P., Freitas, C. L., \& Petri, S. M. (2011). Gestão Ambiental em Instituição de Ensino Superior - Uma Análise da Aderência de uma Instituição de Ensino Superior Comunitária aos Objetivos da Agenda Ambiental na Administração Pública (A3p).

Luiz, L. C. (2014). Plano de gestão de logística sustentável: proposta de um modelo para avaliação do desempenho socioambiental em instituições da rede federal de educação profissional e tecnológica. https://repositorio.ufsc.br/xmlui/handle/123456789/129396

Marques, E. A. F., Vasconcelos, M. C. R. L., Guimarães, E. H. R., \& Barbosa, F. H. F. (2017). Gestão da Coleta Seletiva de Resíduos Sólidos no Campus Pampulha da UFMG: Desafios e Impactos Sociais. Revista de Gestão Ambiental e Sustentabilidade, 6(3), 131-149. https://doi.org/10.5585/geas.v6i3.821

Melo, P. T. N. B., Salles, H. K., \& Van Bellen, H. M. (2012). Quadro Institucional para o Desenvolvimento Sustentável: O Papel dos Países em Desenvolvimento com base na Análise Crítica do Discurso da Rio+20. Cadernos EBAPE.BR, 10(3), 701-720. https://doi.org/10.1590/s1679-39512012000300013

Nogueira, M. V., Moura-Leite, R., \& Lopes, J. C. J. (2019). A Qualidade de Vida no Trabalho sob o Enfoque do Plano de Gestão de Logística Sustentável: Uma Análise das Universidades Federais Brasileiras. Revista de Tecnologia Aplicada, 8(1), 51-70. https://doi.org/10.21714/2237-3713rta2019v8n1p51

OECD. (2010). Organisation for Higher Education for Sustainable Development. Final Report of International Action Research Project.

Oliveira, J. A. P. (2012). "Rio +20: What we Can Learn from the Process and What is Missing." Cadernos EBAPE.BR, 10(3), 492-507. https://doi.org/10.1590/s167939512012000300003

Otero, G. G. P. (2010). Gestão Ambiental em Instituições de Ensino Superior: Práticas dos Campi da Universidade de São Paulo.

Passos. (2009). Declara. Revista Direito Fundamentais \& Democracia, 6(6), 1-25.

Pereira, R. D. S., \& Barbosa, G. E. M. (2018). Plano de Logística Sustentável - PLS: Um Estudo Comparativo em Universidades Federais da Região Metropolitana de São Paulo. Revista Organizações em Contexto, 14(28), 3. https://doi.org/10.15603/19828756/roc.v14n28p3-28

Pereira, R. F. R. (2017). Plano de Gestão de Logística Sustentável em uma Instituição Pública de Ensino.

Pott, C. M., \& Estrela, C. C. (2017). Histórico Ambiental: Desastres Ambientais e o Despertar de um Novo Pensamento. Estudos Avancados, 31(89), 271-283. https://doi.org/10.1590/s0103-40142017.31890021

Silva, B. (1993). A vez de um Pacto Planetário. Revista de Administração de Empresas, 
33(2), 64-75. https://doi.org/10.1590/s0034-75901993000200007

Silva, J. I. A. O., \& Pinheiro, A. L. S. (2018). Avaliação da Sustentabilidade do Instituto Federal de Educação, Ciência e Tecnologia do Rio Grande do Norte. Desenvolvimento em Questão, 16(45), 249-272. https://doi.org/10.21527/2237-6453.2018.45.249-272

Tauchen, J., \& Brandli, L. L. (2006). A Gestão Ambiental em Instituições de Ensino Superior: Modelo para Implantação em Campus Universitário. Gestão \& Produção, 13(3), 503-515. https://doi.org/10.1590/s0104-530x2006000300012

Teixeira, M. G. C., \& Azevedo, P. A. (2013). A Agenda Ambiental Pública: Barreiras para a Articulação entre Critérios de Sustentabilidade e as Novas Diretrizes da Administração Pública Federal Brasileira. REAd, Porto Alegre, 1413(2311), 139-164.

Trigo, A. G. M., Lima, R. D. S. X., \& Oliveira, D. M. (2014). Índice de Sustentabilidade Socioambiental no Ensino. Revista de Administração Da UFSM, 7, 07-22. https://doi.org/10.5902/1983465912771

Vaz, C. R., Fagundes, A. B., Oliveira, I. L., Kovaleski, J. L., \& Selig, P. M. (2010). Sistema de Gestão Ambiental em Instituições de Ensino Superior: Uma Revisão. Revista GEPROS, O(3), 45. https://doi.org/10.15675/gepros.v0i3.327

Warken, I. L. M., Henn, V. J., \& Rosa, F. S. (2014). Gestão da Sustentabilidade: Um Estudo sobre o Nível de Sustentabilidade Socioambiental de Uma Instituição Federal de Ensino Superior. Revista de Gestão, Finanças e Contabilidade, 4(3), 147-166. https://doi.org/10.18028/2238-5320/rgfc.v4n3p147-166

Zagonel, J. T., Safanelli, A. D. S., Andrade, D. F., \& Klaes, L. S. (2019). Desenvolvimento Sustentável e as Instituições de Ensino Superior. 